\title{
Configuração Territorial, Urbanização e Patrimônio: Colônia da Glória (1876- 1904)
}

Walter Pires*

\section{Resumo}

Este artigo apresenta resumidamente os resultados da dissertação de mestrado Configuração territorial, urbanização e patrimônio: Colônia da Glória (1876-1904), defendida no curso da Pós-graduação da Faculdade de Arquitetura e Urbanismo da Universidade de São Paulo.

A pesquisa sobre a formação do território, suas modificações fundiárias e de ocupação, possibilita, em nosso entendimento, ampliar o conhecimento das referências físicas (ambientais, urbanísticas e arquitetônicas) cuja identificação e avaliação são metas dos estudos de preservação do patrimônio histórico e cultural. Assim, configura-se a necessidade de estudos sobre a formação de territórios para identificar a permanência de expressões territoriais. Esse neologismo tenta exprimir os elementos espaciais (lugares) que interagem, influenciam e são influenciados pelos valores sociais e, fundamentalmente, expressam significados que se constituíram ou podem se constituir ainda em valores referenciais e de identificação específicos desse território. Tais elementos conformariam, a partir desse reconhecimento, o objeto de reflexão e de ação das políticas de preservação do patrimônio cultural.

Palavras-chave: Patrimônio cultural. Urbanização. Território.

Territorial Configuration, Urbanization and Heritage: Colônia da Glória (18761904)

This paper shortly presents some of the results contained in the thesis Configuração territorial, urbanização e patrimônio: Colônia da Glória (1876-1904), defended in the graduated course of the Faculdade de Arquitetura e Urbanismo of the Universidade de São Paulo.

The research about the development of territory, and the changes in its property and occupation, leads, in our point of view, to an enlarged knowledge of the physical 
references (natural, urban and architectonic) which identification and evaluation are searched in historic and cultural heritage preservation studies. Therefore, the identification of the permanence of territorial expressions implies the necessity of territory development studies. This neologism tries to clarify the spatial elements (places) which interact, influence and are influenced by social values, and, primarily, express meanings that constitute or may constitute specific references and identity values of this territory. These elements may conform, after this recognition, an object of reflection and action of cultural heritage preservation politics.

Keywords: Cultural heritage. Urbanization. Territory.

Este estudo analisa a organização e o parcelamento territorial do antigo Núcleo Colonial da Glória, criado em 1876, juntamente com outros três núcleos próximos da cidade de São Paulo (Santana, São Caetano e São Bernardo), para abrigar colonos imigrantes. Procurou-se delimitar os condicionantes físicos e históricos que definiram modificações e permanências de certas estruturas fundiárias nos bairros que surgiram na área da Glória, como Cambuci, Jardim da Glória, Chácara Klabin, entre outros.

Identificou-se e estudou-se o intenso processo de concentração fundiária, ocorrido após a emancipação do núcleo colonial em 1878, quando os colonos venderam suas propriedades para novos investidores interessados na valorização dessas terras e em sua urbanização. Esse processo se acelera, num segundo momento, no início do período republicano, entre 1890 e 1893, por causa do chamado Encilhamento, período de euforia financeira e de interesse especulativo, que se expressou na aquisição de grandes glebas, próximas ao centro paulistano. $\mathrm{Na}$ área da Glória esses interesses resultaram, em 1891, no loteamento da Cidade Deodoro, parte do bairro do Cambuci, que, iniciando sua urbanização, definiu a mudança de funções dessa área. Por trás dessas modificações estão investidores e empresas influentes desse período, como Lins de Vasconcellos, Lacerda Franco, Proost Rodovalho, Banco União; além de outros menos estudados como Samuel Eduardo da Costa Mesquita, dentista francês estabelecido no Rio de Janeiro e em 
São Paulo na segunda metade do século XIX, e que exercerá um papel relevante nas alterações fundiárias de parte da Glória.

A recuperação e análise das mudanças e permanências de referências espaciais nesse território permitiram, também, refletir sobre as relações entre configuração territorial e a preservação do patrimônio cultural, e os processos de mediação cultural que definem a permanência ou a destruição dessas referências.

\section{Colônia da Glória: criação e emancipação}

A área da antiga Chácara da Glória, que deu origem ao núcleo de colonização organizado a partir de 1877, corresponde aos atuais bairros do Cambuci, Glória e parte da Aclimação e Vila Mariana, na cidade de São Paulo. No início do século XIX após a morte de seu proprietário, Dom Mateus de Abreu Pereira (1742-1824), Bispo de São Paulo, a propriedade vai à praça (leilão) e é arrematada

pela Fazenda Nacional. O Governo Imperial, através de aviso de oito de janeiro de 1825, decide criar o Seminário das Educandas de Nossa Senhora da Glória, "destinado à educação principalmente de meninas órfãs, filhas de militares que, tendo servido à Pátria, morressem indigentes" (AMARAL, 1980, p. 425-6).

Seminário funciona nesse local, que possuía "boas casas, capela e terras próprias", até 1844, quando é transferido para outros prédios na área central da cidade.

A Chácara da Glória foi transferida pelo Governo Imperial para o Ministério da Agricultura pelo Aviso de 23 de outubro de 1876 com o objetivo de atender ao serviço de colonização. Para efetivar essa medida, no início de 1877, é organizada a Comissão de Medição dos Lotes Coloniais, chefiada pelo engenheiro Leopoldo José da Silva, com o encargo de medir e demarcar a área da colônia, bem como organizar a implantação dos quatro núcleos criados em São Paulo. Alguns meses após o início dos trabalhos da Comissão se deu a criação oficial dos seguintes núcleos: Santana (1ํ de julho de 1877), São Caetano (28 de julho de 1877), Glória (26 de agosto de 1877) e São Bernardo (3 de setembro de 1877). 


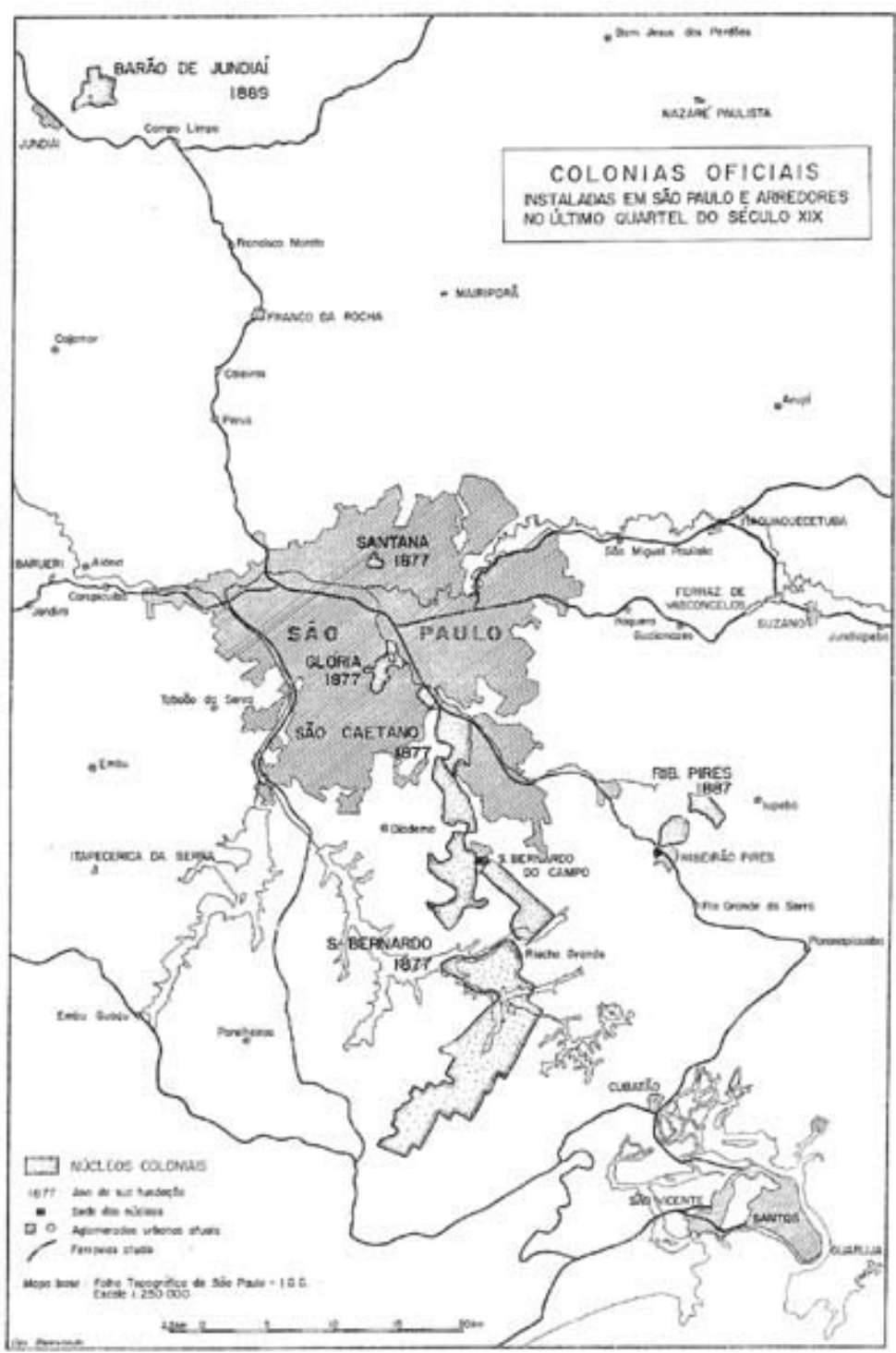

FIGURA 1 - Colónias oficiais instaladas em São Paulo e arredores no último quartel do século XIX. Fonte: LANGENBUCH, Juergen Richard. A estruturação da Grande São Paulo: estudo de geografia urbana. Rjo de Janeiro: IBGE, 1971.

Dificuldades constantes de abastecimento, saúde e organização provocaram episódios de agitação nos núcleos de São Paulo. Esses problemas, associados à opção pela imigração para solucionar o problema da mão-de-obra na expansão cafeeira, levaram à crise e, finalmente, ao abandono da idéia dos núcleos de colonização.

A emancipação do Núcleo Colonial da Glória, em conjunto com o de Santana, se dará oficialmente em 30 de novembro de 1878, menos de três anos após sua criação. Com a emancipação sugerem-se, para a Glória, algumas medidas consideradas importantes para melhorar as condições daquela área, dentre as quais: melhorias no sistema de caminhos internos; remoção do depósito de pólvora, instalando-se no local uma escola pública ou particular subvencionada, para atender 
a filhos de colonos e dos moradores da região; e verificação e regularização das áreas ocupadas por intrusos.

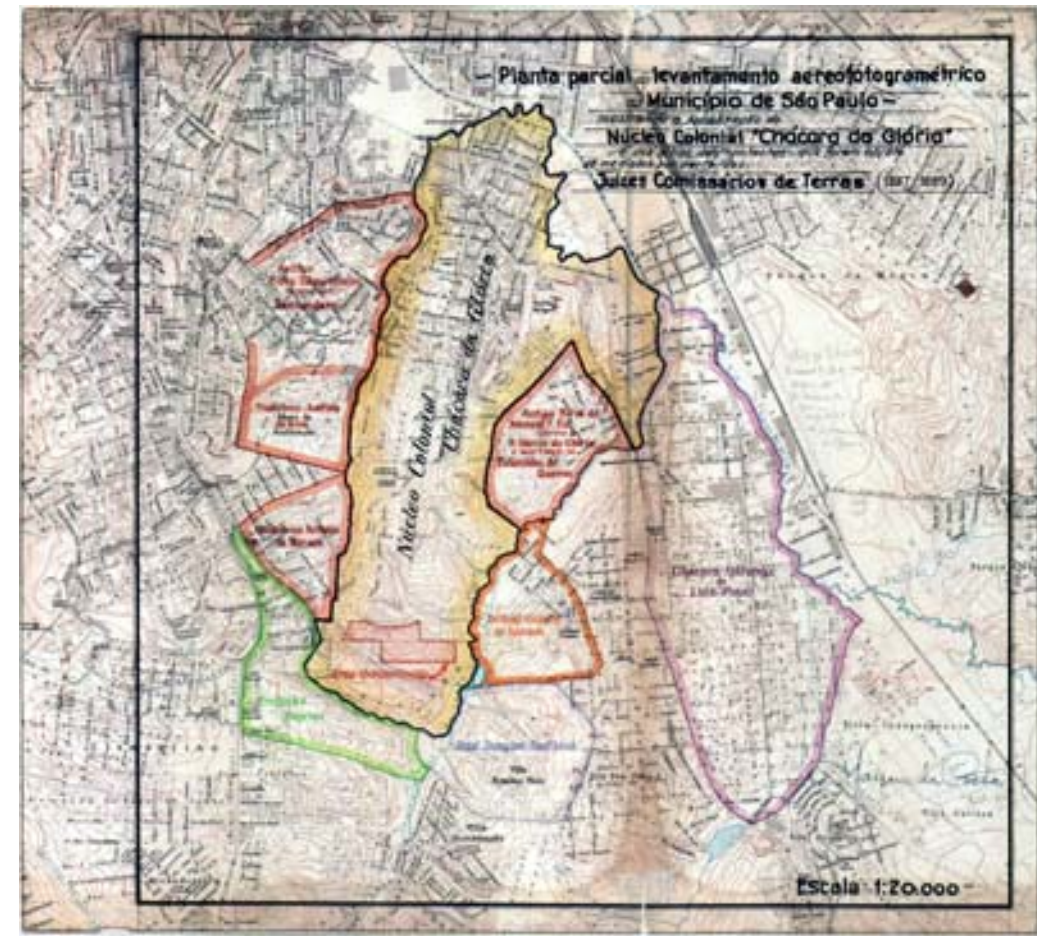

FIGURA 2 - Chácara da Glória e sitios confrontantes que foram objeto de medições por parte dos Juizes Comissários (1887/1889). Fonte: Parecer do eng ${ }^{\circ}$ Jayme da Costa. Processo judicial $n^{0} .2 .275$, de 1951.

\section{A reorganização fundiária da Colônia da Glória - 1876-1893}

Após sua emancipação, a área do núcleo colonial passa por um processo muito rápido de reorganização fundiária. $\mathrm{A}$ análise do modo como se deram as alterações fundiárias na área da Glória - em que momento; quais os envolvidos; que propriedades foram negociadas; em que condições - exigiu um trabalho rigoroso de recuperação dos negócios imobiliários realizados nessa área. Para a organização dessas linhas de sucessão de proprietários foi fundamental a consulta aos dados que compõem o Acervo João Baptista de Campos Aguirra, ou Arquivo Aguirra, como também é conhecido um dos fundos documentais que integram o Serviço de Documentação do Museu Paulista (USP) ${ }^{1}$.

Esse processo de reorganização fundiária se deu em duas etapas:

Primeira etapa (1878 a 1889): neste período uma nova categoria de investidores (comerciantes, capitalistas, profissionais liberais, fazendeiros), interessados na aquisição de chácaras e propriedades não urbanizadas, irá comprar os lotes coloniais diretamente de seus proprietários privados originais (colonos imigrantes), ou através de compra junto ao poder público provincial. As datas que balizam esse período correspondem à emancipação da Colônia da Glória (1878) e à mudança de 
regime político, com a República (1889), que irá redefinir questões econômicas e administrativas que influenciarão o destino dessa área.

Segunda etapa (1890 a 1893): quando se acelera a concentração dessas propriedades, através de sua aquisição por empresas e bancos organizados nesse período, produzindo uma nova configuração territorial. As datas que definem essa etapa correspondem ao início da vigência das novas diretrizes econômicas estabelecidas pela República (1890) e à crise subseqüente desse processo (1893) conhecido como Encilhamento. Em novembro de 1893 registrou-se a última grande negociação imobiliária desse período, entre o Banco União e a Companhia Ipiranga Tramway.

Como área exemplar para a compreensão dos dois períodos de concentração e reorganização fundiárias da Glória, ocorridos entre 1878 e 1893, analisaremos o processo de urbanização da Vila ou Cidade Deodoro, arruamento e loteamento comercializados em 1891, que corresponde à primeira e maior gleba a ser urbanizada no território da extinta Colônia, em seu quadrante norte.

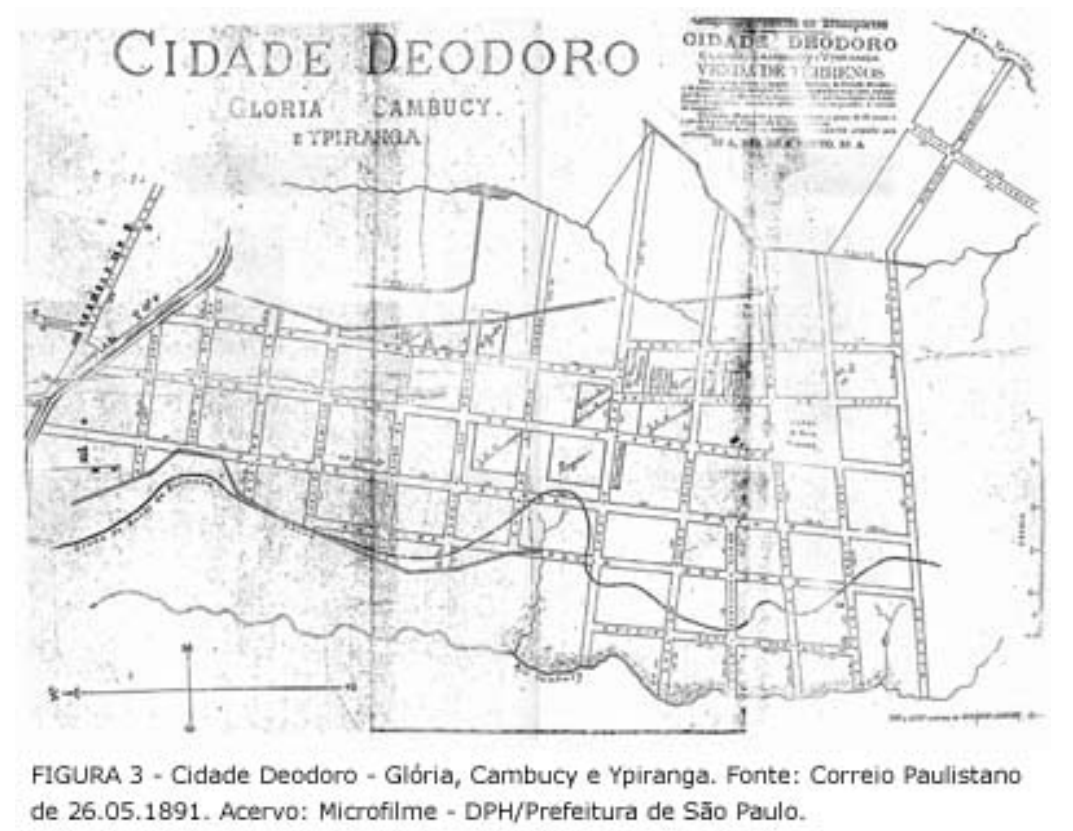

A análise da Vila Deodoro inicia-se pela apresentação de um personagem até agora pouco conhecido na história da formação dos bairros paulistanos: o doutor Samuel Eduardo da Costa Mesquita. Nascido em Paris, em 24 de janeiro de 1838, de família sefardi de origem portuguesa, era filho de Mardochée da Costa e Emilie Athias. O Dr. Samuel Mesquita, como indicam seus anúncios profissionais, teria se formado dentista nas Faculdades de Paris e do Rio de Janeiro. Em diversos almanaques de meados do século XIX há referências sobre seus consultórios 
instalados no Rio de Janeiro, desde 1858 pelo menos, e em São Paulo, a partir de 1870. Samuel Mesquita exerceu as funções provisórias de rabino e integrou a diretoria das primeiras entidades judaicas no Rio de Janeiro e São Paulo. Pode-se inferir, por sua trajetória, ter sido figura de influência e relevo na comunidade judaica. Casa-se em 1873, ainda no Rio de Janeiro, com Mary Amzalak, também integrante de família judia sefardi. Os dados disponíveis revelam que as famílias tinham relações desde o norte da África e que teriam chegado ao Brasil na mesma época. Mesmo que ainda não se possa estabelecer com precisão as motivações que os levaram a investir nessas propriedades ${ }^{2}$ pudemos constatar que, na década de 1880, Samuel Mesquita e sua esposa Mary Amzalak eram donos de vários imóveis: em São Paulo possuíam áreas extensas oriundas do antigo núcleo colonial da Glória. Apenas uma destas glebas media 192.873 m2. Outro dos lotes, de 156.200 m2 será revendido à Cia. City na década de 1910. Em São Caetano também adquirem glebas pertencentes à área do núcleo colonial, e em Santos foram proprietários de imóvel rural denominado José Menino.

A área que foi arruada com o nome de Cidade Deodoro, e cuja venda passou a ser divulgada em 1891, teve origem na fusão e reorganização de alguns dos grandes lotes rurais do núcleo colonial da Glória, destacando-se a grande propriedade organizada por Samuel Eduardo da Costa Mesquita, conhecida como Monte Belo do Cambuci. A Cia. Paulista de Transportes adquiriu, além desta grande gleba, outra conhecida como bairro do Rincão. Em escritura de 29 de abril de 1891 estes dois lotes perfazem uma área total de $1.514 .634 \mathrm{~m} 2$, no valor de $\mathrm{R} \$$ 2.200:000\$000.

A Cia. Paulista de Transportes foi constituída em agosto de 1890, poucas semanas antes das aquisições descritas, tendo como sócios incorporadores Domingos Luiz da Costa e Roberto Le Vinger (LÉRIAS, 1988). Para a assinatura da escritura a empresa foi representada por Luiz de Oliveira Lins de Vasconcellos e Antonio Proost Rodovalho. Os objetivos da empresa eram a "venda de terrenos em Cidade Deodoro, Glória, Cambuci e Ipiranga; e o estabelecimento de uma linha de bondes entre a Sé e o Ipiranga", e teria ido a liquidação no mesmo ano de lançamento do loteamento Cidade Deodoro (BRITO, 2000, p. 15).

O desenho geral da proposta de parcelamento da Cidade Deodoro desenvolve-se em torno das avenidas Lins de Vasconcelos e Lacerda Franco, implantadas no divisor de águas entre os córregos do Cambuci e do Cortume, e que 
irão efetivamente transformar-se, ao longo do tempo, nas duas vias principais desse trecho do bairro. A avenida Lins de Vasconcelos será a ligação mais importante, pois, iniciando-se no largo do Cambuci e aproveitando parte do traçado da antiga estrada da Colônia da Glória (aberta para viabilizar a implantação do núcleo colonial), cortará toda a área da Vila Deodoro e dos futuros loteamentos realizados nos outros lotes rurais, até encontrar-se com a estrada do Vergueiro, na Vila Mariana. O traçado geral do arruamento é simples, em tabuleiro de xadrez, e com algumas soluções urbanísticas pouco racionais que ocasionaram descontinuidade no alinhamento de algumas ruas ou na sua interrupção abrupta junto aos limites da gleba. Este arruamento assemelha-se aos de alguns bairros que tinham sido recentemente abertos na vizinhança do centro da cidade, em traçado hipodâmico tais como Santa Efigênia, Campos Elíseos, Higienópolis e Vila Buarque.

A análise de processos de modificação fundiária ocorridos em outros lotes rurais da antiga Colônia da Glória (principalmente aqueles situados no quadrante sul da Glória - lotes 108 a 115) revela que a intensidade e o modo como se deu o movimento de comercialização e concentração dessas terras, em 1890, foi muito semelhante ao que ocorreu em Vila Deodoro.

Contudo, duas diferenças podem ser apontadas entre essas áreas: a primeira é que não se efetivou de imediato o parcelamento possivelmente pretendido. Algumas dessas áreas, como o atual bairro Chácara Klabin, terão que esperar 70 anos, até a segunda metade do século $X X$, para serem urbanizadas ${ }^{3}$. Longas disputas judiciais caracterizaram a ocupação dessa área da Glória. A mais demorada é a que foi movida por João Bottecchia e seus herdeiros contra os sucessores de Mauricio F. Klabin e a própria Municipalidade de São Paulo. Prolongou-se por cerca de 20 anos e, por fim, os herdeiros de Klabin obtiveram a reintegração de posse na década de 1960. É a área do lote 112, que corresponde atualmente ao loteamento denominado Chácara Klabin. 


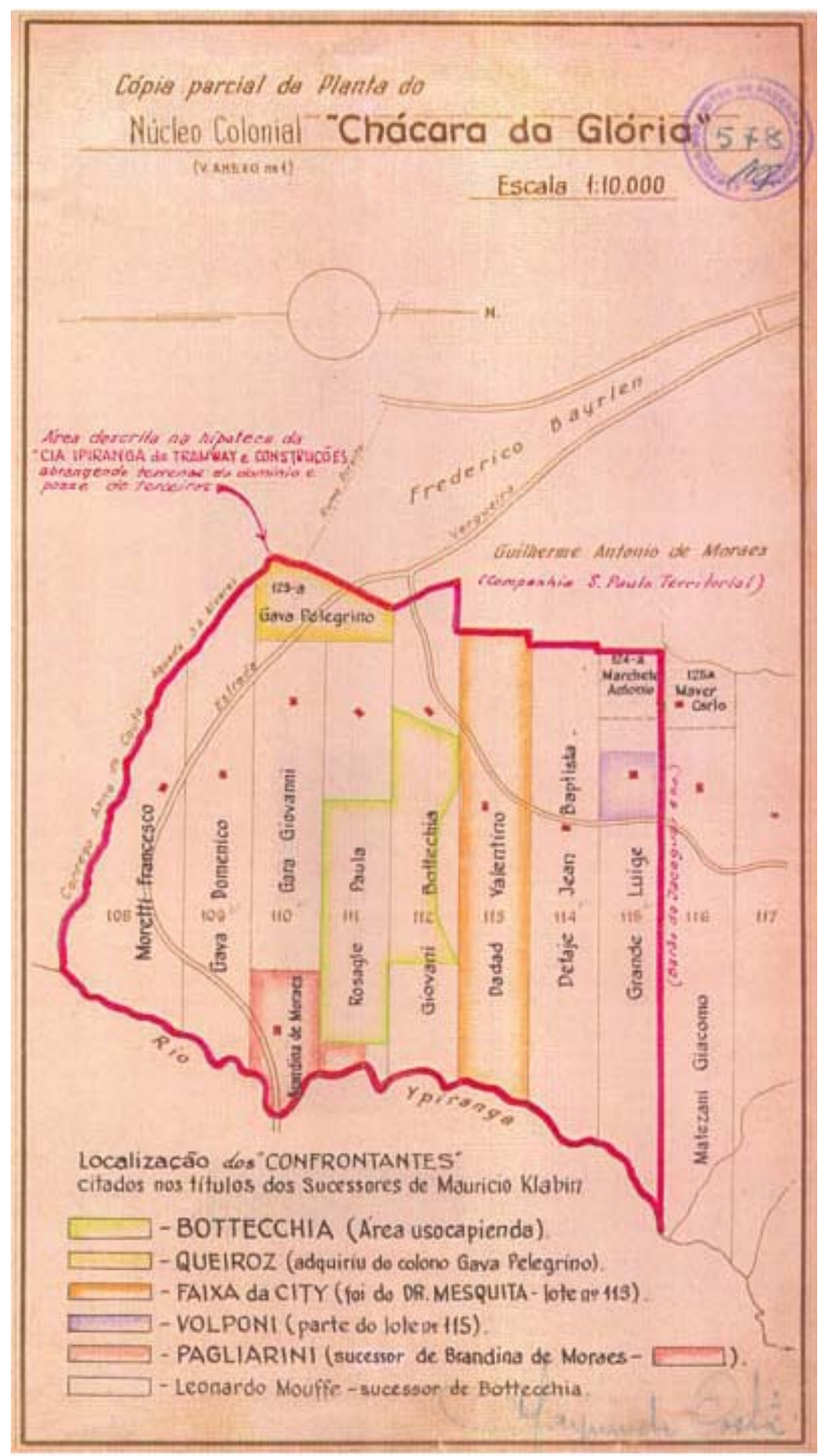

FIGURA 4 - Nủcleo Colonial da Glária - Área sul com localização dos confrontantes citados nos titulos dos sucessores de Mauricio Klabin. Fonte: Eng ${ }^{\circ}$ Jayme da Costa. Processo judicial no. 2.275, de 1951.

A segunda diferença refere-se à aquisição dos diversos lotes: a maioria foi comprada, em 1890, diretamente dos antigos colonos ou seus sucessores. E isto se deu por um mesmo grupo de investidores associados que, em curto prazo, transferiram essas propriedades como forma de participação acionária para a Cia. Ypiranga de Tramways e Construções. 
Samuel Eduardo da Costa Mesquita representa, exemplarmente, o primeiro momento de concentração privada de terras e a Cia. Paulista de Transportes, incorporadora da área conhecida por Vila Deodoro, o momento seguinte, de cunho empresarial. Neste exemplo de sucessão de propriedade entre Mesquita e a Cia. Paulista, o processo de concentração e transferência se deu na mesma gleba, resultante da junção de vários lotes rurais e urbanos originais, situados na porção norte da Glória.

A valorização dessas terras, estimulada pelo interesse na área da Glória como espaço para crescimento urbano, não beneficiou os antigos colonos, primeiros proprietários desses lotes. Mesmo considerando que o preço pelos quais estes venderam suas propriedades possa ter representado um ganho, tendo em vista sua condição econômica, e tenha estimulado a realização desses negócios, a valorização mais significativa se dará nas sucessivas transferências de propriedade, através dos intermediários e, finalmente, para os investidores na urbanização ${ }^{4}$.

\section{Configuração territorial da área da Glória: mudanças e permanências}

Uma das motivações que impulsionou este trabalho foi o desejo de compreender o que determina que certas referências espaciais de um território adquiram valores para um grupo social, a ponto de justificar sua preservação como patrimônio cultural.

Consideramos, e a proposta da dissertação estruturou-se nessa hipótese, que compreender a origem da ocupação desse território, a sucessão e os condicionantes das alterações fundiárias, e as características da nova configuração territorial organizada, seria subsídio relevante ao entendimento desse espaço e de sua "expressão territorial".

A escolha desse modelo de abordagem e a preocupação centralizada nas sucessões fundiárias e dos personagens envolvidos conduziram, com o avanço do trabalho, à constatação de que a persistência de certas características espaciais e sua eventual atribuição de significado para a preservação se dava no embate entre modificação e permanência. Embate, aliás, que é a essência do conceito de proteção do patrimônio: o tenso debate sobre os limites entre alteração e preservação dos bens culturais. 
No caso da Glória, em pouco menos de vinte anos (1876-1893), esta se configura:

a) Como chácara: uma unidade fundiária bem delimitada, que se diferencia também por ser pública. Mas, como função e apropriação social, seus limites como território apresentam certa indefinição, tanto pelo uso como pastagens ou potreiros, semelhantes às outras propriedades vizinhas, como pela própria penetração de "intrusos" ao longo do tempo, aproveitando-se dessa condição "pública". Que formas a memória social relaciona com a chácara? Pastagens; pousos; passagem e caminho; capela e seminário; ruínas e fantasmas românticos; abandono; desinteresse. O nome, Glória: permanência renitente de origem religiosa.

b) Como colônia: o núcleo colonial como unidade administrativa em organização, cujo resultado final é a divisão, o parcelamento dentro de um projeto racional (plano). O plano inicia a configuração de novos territórios (modificação): a organização da produção agrícola; a separação do rural e do urbano; a resolução das ocupações irregulares (permanências). Há uma vontade oficial de inserção, no território mais amplo da cidade, de propriedades agrícolas organizadas. Uma outra função; um outro desenho fundiário; um outro grupo social, os imigrantes; uma outra relação de propriedade da terra. A emancipação finalmente acelera o "fracasso" do núcleo agrícola e a passagem do solo público para o privado. O novo território se organiza com clareza: a fluidez e rapidez dos negócios imobiliários modificando, no ritmo da decisão do indivíduo no mercado, e fragmentando o que permanecera, pelo menos durante três séculos, como unidade. Que formas a memória social preserva da colônia? Imigrantes e colonos; expectativa de produção agrícola; lotes rurais e lotes urbanos; caminhos, casas e plantações; conflitos; "indolência" e fracasso; novas expectativas com a urbanização; Casa da Pólvora; o caminho para o Monumento do Ipiranga.

c) Como cidade: perdeu-se a unidade física e formal da chácara e a unidade de plano e intenções da colônia. Reconfigura-se a área colonial dividida em novas e extensas unidades, para um movimento imediato de nova e maior fragmentação: os lotes urbanizados. Unifica-se, concentra-se a propriedade para dividi-la em seguida é o exemplo da Cidade Deodoro. Uma nova e decisiva mudança de função: a passagem do rural ou natural para o urbano. Mas, novamente e sempre, a modificação não se dá sem embate e as disputas de propriedade o exprimem: é a permanência de fragmentos de um espaço e tempo distintos (Bottechia) coexistindo 
com o novo território urbano em projeto e desejo (Klabin). Fragmentam-se e perdemse definitivamente as unidades anteriores: loteamentos isolados; permanência de pequenas chácaras; o conflito preparando, no futuro, a grande favela (Vergueiro). A cidade em sua diversidade funcional irá se consolidar. $O$ que a memória social registra dessa cidade? A ansiedade e rapidez para a transformação em "cidade"; o ritmo efetivo de formação do bairro; disputas de terras; a toponímia autoreferenciadora dos loteadores (Lins de Vasconcelos, Lacerda Franco, Mesquita, Inglês de Souza).

É a partir do momento definidor da urbanização e sua complexidade que irá se configurando - através dos loteamentos, seu adensamento e ocupação social da área da Glória - uma nova espacialidade: são as casas, escolas, igrejas, comércio, os cemitérios, hospitais, campos de futebol em áreas baldias, enfim, a diversidade caracterizadora do espaço urbano construindo novas formas - materiais e imateriais - de convivência.

De outra parte, mesmo o que permaneceu em alguns desses momentos não se deu por uma "consciência" do valor e do significado histórico, paisagístico ou cultural: a sede da chácara, sua capela e suas alfaias desapareceram (onde estão as imagens sacras cuidadosamente registradas em 1824?); a capelinha onde os colonos oravam em 1880, também; a Casa da Pólvora e o primeiro hospital militar, idem. Bens materiais que, adotando a racionalidade de critérios atuais de preservação do patrimônio, poderiam ser considerados "significativos".

Destaque-se, porém, que a estruturação territorial da Glória, e a documentação mostra isso, dependeu, em parte, da construção de um marco importante da memória oficial: o Monumento à Independência no Ipiranga. A organização espacial da área da várzea do Cambuci foi condicionada pelo desenho do acesso e pela valorização visual do conjunto do Ipiranga. No período analisado essa questão estava colocada com muita intensidade na sociedade paulistana. Não se trata, naquele momento (1880-1890), de preservação de algo material, mas de construção de um bem físico para preservação da memória de uma expressão imaterial, um caso típico de monumento intencional.

É contemporaneamente que a sociedade se organiza para criar seus monumentos; identificar, atribuir e assumir a responsabilidade de preservar do esquecimento ou da modificação descaracterizadora as referências espaciais com significados considerados relevantes. Essa preocupação se aguça no momento 
crucial do risco iminente de perda dessas referências: momento freqüentemente associado ao embate já referido, entre modificação e permanência.

Essa nova forma de se relacionar com o passado, com a memória e com as "expressões territoriais" do viver coletivo exige, portanto, uma mediação cultural e social, que passa a participar e influir naquele embate.

De um lado, novamente se manifesta o desejo / vontade de se ter, em potência, o novo (aquilo que existirá): de um modo positivo como busca do sonho, da imaginação, do aperfeiçoamento; como desejo válido de ruptura do estabelecido (Ícaro, com todos os riscos, voando para longe do labirinto...). Mas, também, correndo o risco de se tornar busca inconseqüente do "moderno pelo moderno", apenas.

No campo oposto o desejo / vontade de manter, na realidade dada, o existente (aquilo que existe): como respeito ao resíduo do esforço e do saber humanos do passado (John Ruskin...); como inspiração, conhecimento transmissível e equilíbrio; como abrigo do desconhecido. Mas, também, acomodando-se na passividade, no costume, no medo da mudança e desse desconhecido. O risco e a ameaça da perda.

A boa construção é lenta - exige vontade, conhecimento, disciplina, técnica, colaboração; e seu resultado sempre expressa uma arte coletiva (mesmo que não se saiba ou tenha se esquecido). É acumulação, correção e avanço. A destruição é rápida - é irreversível; pode ser irracional e impulsiva. Existe, porém, a destruição que precede a boa construção. Como discernir?

A partir dessa complexa e contraditória disputa entre mudança e permanência, que em cada momento e lugar se instaura no momento do risco, é que se deve dar a escolha. Esse é o enigma, a pedra de fecho que, misteriosamente, só se conclui junto com o próprio arco que sustenta.

E se nessa tensa oscilação entre a modificação e a permanência, entre a construção e a destruição, as expressões escolhidas pela sociedade para significá-la estiverem reduzidas a poucos e pobres fragmentos, talvez reste refletir sobre os versos de alguém que construiu, certamente, bem mais do que destruiu:

E, afora este mudar-se cada dia, outra mudança faz de mor espanto: que não se muda já como soía... Camões (Soneto 21) 


\section{Notas}

'João Baptista de Campos Aguirra (1871-1958) organizou ao longo de sua vida, para seu interesse profissional, assessorando negócios imobiliários, e para seu objetivo como pesquisador da história paulista, um extenso conjunto de documentos (fichas, cadernos, relatórios, plantas e mapas, livros) relacionados à organização fundiária de São Paulo. Consultando arquivos públicos, cartoriais e particulares, reproduziu minuciosamente esses dados que, após a sua morte, foram incorporados ao acervo do Museu Paulista. Ver Walter Pires, Arquivo Aguirra. Fonte documental sobre a formação territorial de São Paulo, Anais do Museu Paulista. São Paulo. N. Sér. v. 10/11. p. 61-78 (2002-2003).

${ }^{2}$ Nas pesquisas realizadas por Egon e Frieda Wolff, há uma informação isolada, publicada no jornal Le Brésil Republicain, de 24/06/1891, que afirma ter o dr. Samuel Mesquita conseguido junto ao Presidente do Estado algumas glebas de terras, em São Paulo, para fixar 80 famílias de judeus russos. Esse dado foi muito instigante para estimular reflexões e para a pesquisa das motivações de Samuel e sua família no investimento em terras em São Paulo. Contudo, não há registros familiares sobre essa questão e nenhum outro dado foi localizado confirmando a obtenção dessas glebas.

${ }^{3}$ Os interesses de Mauricio F. Klabin nessa área se concretizam quando este adquire, em 1904, um expressivo número das propriedades na região da Glória, Vila Mariana e Ipiranga que pertenciam ao Banco União desde 1893.

${ }^{4}$ Para exemplificar a extrema valorização especulativa dessas terras temos o caso dos lotes coloniais de números 108 a 111, cujo valor por m2, entre 1884 e 1890, aumentou entre 500 e 800 vezes.

\section{Referencias Bibliográficas}

\section{Fontes Documentais}

Arquivo do Poder Judiciário de São Paulo - Processos judiciais referentes a questões de terras na área da Glória: №. 2.275, de 1951; №. 4.669, de 1965; №. Ordem 783.

Arquivo Geral da Prefeitura de São Paulo (DAF) - Processos relativos a loteamentos na área da Glória: №. 36.858/1931; №. 51.161/1933; №. 40.189/1938; №. 66.157/1938.

Arquivo Histórico Municipal / Departamento do Patrimônio Histórico - Acervo Cartográfico - plantas microfilmadas da área do Cambuci e Glória.

Departamento de Cadastro Setorial - CASE / SEHAB / Prefeitura de São Paulo - Cadastro de loteamentos fichas e plantas diversas sobre loteamentos da área

Departamento do Arquivo do Estado de São Paulo Fundo Colônias - Período - Caixas CO 721027216

IGC - Instituto Geográfico e Cartográfico - Acervo cartográfico e aerofotogramétrico - conjunto de aerofotos de vôo realizado em 1954 pelas empresas VASP e Cruzeiro do Sul 
Museu Paulista / USP- Serviço de Documentação - Acervo do Arquivo Aguirra

\section{Bibliografia Geral}

AMARAL, Antonio Barreto do. Dicionário de história de São Paulo. São Paulo : Governo do Estado, 1980.

AZEVEDO, Aroldo de (Org.). A cidade de São Paulo : estudos de geografia urbana. São Paulo : Nacional, 1956.

BRITO, Mônica Silveira. A participação da iniciativa privada na produção do espaço urbano: São Paulo, 18901911. 2000. Dissertação (Mestrado em Arquitetura e Urbanismo) - Faculdade de Arquitetura e Urbanismo, Universidade de São Paulo, São Paulo, 2000.

DINIZ, Firmo de Albuquerque (Junius). Notas de viagem. Introdução de Antonio Barreto do Amaral. Ed. facsimilar. São Paulo : Governo do Estado, 1978.

DOREA, Augusta Garcia Rocha. Aclimação. São Paulo : Departamento do Patrimônio Histórico, 1982.

LANGENBUCH, Juergen Richard. A estruturação da Grande São Paulo : estudo de geografia urbana. Rio de Janeiro : IBGE, 1971.

LÉRIAS, Reinéro Antônio. O Encilhamento e a cidade de São Paulo, 1890-1891. 1988 Dissertação (Mestrado em História Social) - Faculdade de Filosofia, Letras e Ciências Humanas, Universidade de São Paulo, São Paulo, 1988.

MARTINS, José de Souza. Subúrbio : vida cotidiana e história no subúrbio da cidade de São Paulo : São Caetano : do fim do Império ao fim da República Velha. 2. ed. São Paulo : Hucitec : Unesp, 2002.

MARX, Murillo. Cidade no Brasil, em que termos? São Paulo : Studio Nobel, 1999.

MONTEIRO, Zenon Fleury. Reconstituição do Caminho do Carro para Santo Amaro. São Paulo : Prefeitura do Município, 1943.

RAFFARD, Henrique. Alguns dias na Paulicéia. Introdução de Leonardo Arroyo. São Paulo : Academia Paulista de Letras, 1977.

RELATÓRIOS apresentados pela Secretaria de Estado dos Negócios da Agricultura, Comércio e Obras do Império nos anos de 1876, 1877, 1878 e 1879. Disponível em: <http://brazil.crl.edu/bsd/bsd/hartness/agricultura.html>. Acesso em 21.04.2001.

RELATÓRIOS apresentados à Assembléa Legislativa Provincial de S. Paulo pelos Presidentes da Província nos anos de 1875, 1876, 1877, 1878, 1879, 1880, 1881, 1882 e 1883. Disponível em: $<$ http://www.crl.edu/content/brazil/sao.htm>. Acesso em 21.04.2001. 
SAES, Flávio Azevedo Marques de. Crédito e bancos no desenvolvimento da economia paulista : 1850-1930. São Paulo : Instituto de Pesquisas Econômicas, 1986.

A grande empresa de serviços públicos na economia cafeeira : um estudo sobre o desenvolvimento do grande capital em São Paulo : 1850 - 1930. 1979. Tese (Doutorado em Sociologia) - Faculdade de Filosofia, Letras e Ciências Humanas, Universidade de São Paulo, São Paulo, 1979.

SALLES, Maria Izabel Bernardes Moreira. Santana: imigração e colonização: um núcleo paulista de colonização oficial. [199-?]. Dissertação (Mestrado em História) - Faculdade de Filosofia, Letras e Ciências Humanas, Universidade de São Paulo, São Paulo.

SAMPAIO, Maria Ruth Amaral de. O papel da iniciativa privada na formação da periferia paulistana. Espaço \& Debates : Revista de Estudos Regionais e Urbanos, São Paulo, v. 14, n. 37, p. 19-33, 1994.

SILVA, Lígia Osorio. Terras devolutas e latifúndio : efeitos da lei de 1850. Campinas : Unicamp, 1996.

VARELA, Fagundes. As ruínas da Glória: conto phantástico. In: LISBOA, José Maria. Almanach Litterario de São Paulo para o anno de 1885. Ed. fac-sim. São Paulo : IMESP/IHGSP, 1982.

VERAS, Lúcia Maria de Siqueira Cavalcanti. De Apé-Puc a Apipucos : numa encruzilhada, a construção e permanência de um lugar urbano. Recife : Bagaço, 1999.

WOLFF, Egon. Coletânea de artigos e conferências. Rio de Janeiro : Instituto Histórico e Geográfico Brasileiro, 1991.

WOLFF, Egon ; WOLFF, Frieda. Dicionário biográfico. Rio de Janeiro : Ed. dos Autores, 1987. v.2 - Judeus no Brasil, século XIX.

Os judeus no Brasil Imperial : uma pesquisa nos documentos e no noticiário carioca da época. São Paulo : Centro de Estudos Judaicos, FFLCH/USP, 1975.

\section{ENTREVISTAS}

Descendentes de Samuel Eduardo da Costa Mesquita e Luiz de Oliveira Lins de Vasconcellos: Antonio Carlos Gama Rodrigues - novembro de 2002; Marita Simy Gama - novembro de 2002 e fevereiro de 2003; Antonio Luiz Lins de Vasconcellos - fevereiro de 2003; Maria Regina Mellone - fevereiro de 2003.

* Arquiteto. Mestre pela FAU-USP. Diretor técnico do DPH / SMC / PMSP 